\title{
A New Low-Molecular-Weight Component Promoting Adrenergic Development in Cultured Chick Sympathetic Neurons
}

\author{
A. D. Zurn \\ Department of Biochemistry, Sciences II, CH-1211 Geneva 4, Switzerland
}

\begin{abstract}
A low-molecular-weight component present in medium conditioned by cultured chick liver cells (LCM) enhances the adrenergic properties of dissociated chick superior cervical ganglion (SCG) neurons in culture (Zurn and Mudry, 1986). This substance cannot replace NGF as a survival, growth, or differentiation factor. However, in the presence of NGF, it stimulates neuronal metabolism and catecholamine (CA), but not ACh production by the SCG neurons. The effect on transmitter production is greater than that on neuronal metabolism. Yet this is not due to an increase in the specific activity of tyrosine hydroxylase (TH), the rate-limiting enzyme in CA synthesis. Interestingly, the effect of LCM on CA and ACh production, but not on neuronal metabolism, is potentiated in the presence of a large excess of NGF. The active component(s) present in LCM has a molecular weight lower than $500 \mathrm{Da}$ and is not inactivated by heat or pronase treatment. So far, none of the small molecules tested (ascorbic acid, pyruvate, glucose, L-glutamic acid, glutathione, etc.) were able to mimic the effects of LCM on the SCG neurons. Thus this report describes a novel low-molecularweight component different from NGF that promotes metabolism and adrenergic development in cultured chick sympathetic neurons.
\end{abstract}

Understanding the molecular mechanisms that underlie neuronal development and lead to complex and highly specific interactions in the nervous system is of great importance. In the last decade it has become clear that both intrinsic (genetic) and extrinsic (environmental) factors can influence the development of the brain by affecting neuronal migration, survival, neurite outgrowth, neuronal growth, and/or differentiation.

The best-characterized environmental factor is a diffusible neurotrophic substance, NGF, which is essential for the survival, growth, and differentiation of sympathetic, and a subpopulation of sensory, neurons (for reviews, see Thoenen and Barde, 1980; Yankner and Shooter, 1982). Neurotrophic factors that exclusively promote neuronal differentiation, i.e., factors that control the type and/or the amount of neurotransmitter synthesized by neuronal cells, have also been described: a cholinergic differentiation factor is present in medium conditioned by

Received Sept. 26, 1986; revised May 4, 1987; accepted May 5, 1987

I wish to thank Dr. M. Schwab and Dr. A. Kato for comments on the manuscript, Dr. Y. A. Barde for supplying 2.5 S NGF, Dr. L. Wuarin for analyzing the effect of LCM on cultured chick spinal cord neurons, and L. Munkoe for excellent technical assistance. This work was supported by the Swiss National Foundation for Scientific Research (Grants 3.433-0.83 and 3.151-0.85 to A.D.Z.).

Correspondence should be addressed to A. D. Zurn, Department of Biochemistry, Sciences II, 30, quai E. Ansermet, CH-1211 Geneva 4, Switzerland.

Copyright $\odot 1987$ Society for Neuroscience $0270-6474 / 87 / 113566-08 \$ 02.00 / 0$ cultured rat heart cells or superior cervical ganglion (SCG) nonneuronal cells. This factor induces cholinergic properties in cultured rat SCG neurons that are initially purely adrenergic (Patterson and Chun, 1977). It has recently been purified and partially characterized (Fukada, 1985; Weber et al., 1985).

Several environmental factors have been shown to induce or promote adrenergic properties in cultured neural crest cells, neuronal precursor cells, or differentiated neurons: (1) fibronectin, glucocorticoids, chick embryo extract, and neural tube-conditioned medium either stimulate or induce adrenergic differentiation in neural crest cells (Sieber-Blum et al., 1981; Smith and Fauquet, 1984; Howard and Bronner-Fraser, 1986); (2) a small percentage of precursor cells from quail dorsal root ganglia (which do not normally contain adrenergic neurons) develop into adrenergic cells, provided that chick embryo extract is present in the culture medium (Xue et al., 1985; Rohrer et al., 1986); (3) adrenergic properties are increased in adrenal chromaffin cells or sympathetic neurons cultured at a high cell density, on laminin-coated tissue culture dishes, in the presence of high NGF, high $\mathrm{KCl}$ concentrations, glucocorticoids, or medium conditioned by chick liver cells in culture (LCM) (Otten and Thoenen, 1976; Hefti et al., 1982; Acheson and Thoenen, 1983; Acheson et al., 1986; Zurn and Mudry, 1986).

So far, only a few neurotrophic factors have been characterized biochemically. Most of them are macromolecules with molecular weights ranging from 12,300 to $56,000 \mathrm{Da}$ (Thoenen and Barde, 1980; Barde et al., 1982; Barbin et al., 1984; Fukada, 1985; Gurney el al., 1986). However, several very low-molecular-weight neurotrophic components have been described recently. Pyruvate, for instance, appears to be the main trophic component of glia-conditioned medium, which is responsible for the survival of central nervous system neurons cultured in the absence of recognized protein neurotrophic factors (Selak et al., 1985). Ascorbate, the cofactor of the enzyme dopamine- $\beta$ hydroxylase, increases the epinephrine and norepinephrine content of cultured adrenal chromaffin cells (Wilson and Kirshner, 1983).

In the present report we show that medium conditioned by cultured chick liver cells (LCM) contains a novel low-molecularweight neurotrophic substance that promotes neuronal metabolism and adrenergic development in dissociated chick SCG neurons cultured in the presence of NGF. This component cannot replace NGF as a survival, growth, and differentiation factor for the SCG neurons, but it acts in a synergistic fashion with NGF to promote the growth and adrenergic development of these cells. Furthermore, it appears to be specific for sympathetic neurons, since it does not increase neuronal metabolism or induce catecholamine (CA) production in chick ciliary ganglion, dorsal root ganglion, and spinal cord neurons. 


\section{Materials and Methods}

\section{Cultures}

SCG from 9-d-old chick embryos were dissociated with trypsin, centrifuged on a Percoll density gradient to remove non-neuronal cells, and cultured as described previously (Zurn and Mudry, 1986). Briefly, the SCG neurons were plated at a density of 100-120,000 cells/well and grown for 2-3 weeks on $16 \mathrm{~mm}$ multiwell plastic tissue culture dishes (Costar) precoated with polyornithine and chick heart cell-conditioned medium. The culture medium consisted of either complete MEM, containing $1.5 \%(\mathrm{vol} / \mathrm{vol})$ fetal calf serum, $1.5 \%$ horse serum, $35 \mathrm{~mm} \mathrm{KCl}$, and NGF $(1 \mu \mathrm{g} / \mathrm{ml} 7 \mathrm{~S}$ or $10 \mathrm{ng} / \mathrm{ml} 2.5 \mathrm{~S})$, or the same medium supplemented with LCM (Zurn and Mudry, 1986).

The ciliary ganglion neurons were cultured as described by Kato and Rey (1982), except that the eye extract was dialyzed overnight against saline to remove the low-molecular-weight neurotrophic factor that is also present in eye extract. Dorsal root ganglion neurons were cultured as described by Sonderegger et al. (1984), and spinal cord neurons according to the method of Kato et al. (1985), except that $10 \%$ fetal calf serum was used instead of human serum.

\section{Preparation and ultrafiltration of $L C M$}

Liver cells from 9-d-old chick embryos were cultured in the presence of 10\% horse serum, as described previously (Zurn and Mudry, 1986). Medium conditioned by those cells, LCM, was removed after 3 and 5 $\mathrm{d}$, centrifuged for $30 \mathrm{~min}$ at $16,000 \times g$ (Sorvall), and kept frozen at $-20^{\circ} \mathrm{C}$ (complete LCM). A low-molecular-weight fraction of the LCM was prepared by filtering the conditioned medium through an Amicon YC05 ultrafiltration membrane having a molecular weight cutoff of 500 Da. The filtrate $(\mathrm{L} 500)$ was kept frozen at $-20^{\circ} \mathrm{C}$.

\section{Measurement of neuronal metabolism}

Cell body diameter. Estimates of cell body diameter were based on measurements of long and short somatic axes on photographs taken with a phase-contrast microscope $(200 \times$ magnification). Only phasebright cells with one or more processes were counted.

Lactate dehydrogenase activity. The activity of lactate dehydrogenase $(\mathrm{LDH})$, used as a marker of neuronal growth and metabolism, was measured as described by Nishi and Berg (1981a). One LDH unit corresponds to the LDH activity expressed in optical density $(\mu \mathrm{m}) / \mathrm{min} /$ neuron (decrease in the absorbance of light at $340 \mathrm{~nm}$ ).

${ }^{3} \mathrm{H}$-leucine incorporation. SCG cultures, 2-3 weeks old, were incubated overnight with $0.6 \mu \mathrm{M} \mathrm{L}-4,5-{ }^{3} \mathrm{H}$-leucine $(120 \mathrm{Ci} / \mathrm{mmol}$; Amersham, England) in leucine-free medium supplemented with $100 \mu \mathrm{M}$ unlabeled leucine and all the ingredients present in the complete culture medium, except for the amino acid mix and the LCM or L500 (lowmolecular-weight fraction of the liver-conditioned medium after filtration on a YC05 Amicon ultrafiltration membrane). The amount of radioactivity incorporated into proteins was determined after extraction of the neurons in saline containing $1 \%$ SDS, precipitation with trichloroacetic acid (TCA), and counting in a Beckman liquid-scintillation counter. It was expressed in femtomoles of ${ }^{3} \mathrm{H}$-leucine per neuron $/ \mathrm{hr}$.

Measurement of transmitter production. Synthesis and accumulation of $\mathrm{CA}$ and $\mathrm{ACh}$ by the SCG neurons were measured by high-voltage electrophoresis after incubation of 2-3-week-old cultures for $4 \mathrm{hr}$ with the radiolabeled precursors ${ }^{3} \mathrm{H}$-tyrosine and ${ }^{3} \mathrm{H}$-choline (Amersham, England), as described by Mains and Patterson (1973). LCM and L500 were not present during the $4 \mathrm{hr}$ incubation period (Zurn and Mudry, 1986). [Norepinephrine (NE) and dopamine are not completely separated by the electrophoretic procedure used (Hildebrand et al., 1971) and are thus not analyzed separately in this paper.]

Determination of tyrosine hydroxylase activity. Tyrosine hydroxylase (TH) activity was measured by following the formation of ${ }^{14} \mathrm{CO}_{2}$ from $\mathrm{L}-1-{ }^{14} \mathrm{C}$-tyrosine (Amersham, England) in the presence of an excess hog kidney DOPA decarboxylase, as described by Swerts et al. (1983). The radioactivity was expressed in femtomoles of ${ }^{14} \mathrm{CO}_{2}$ produced per neu$\mathrm{ron} / \mathrm{min}$.

Materials. Complete, leucine-free, and tyrosine- and choline-free MEM were purchased from Gibco. NGF, $7 \mathrm{~S}$, was isolated from mouse saliva as described by Burton et al. (1978); 2.5 S NGF was the gift of Dr. Y. A. Barde, Max-Planck-Institut, Munich. If not otherwise stated, all reagents, including protease from Streptomyces griseus, were obtained from Sigma.

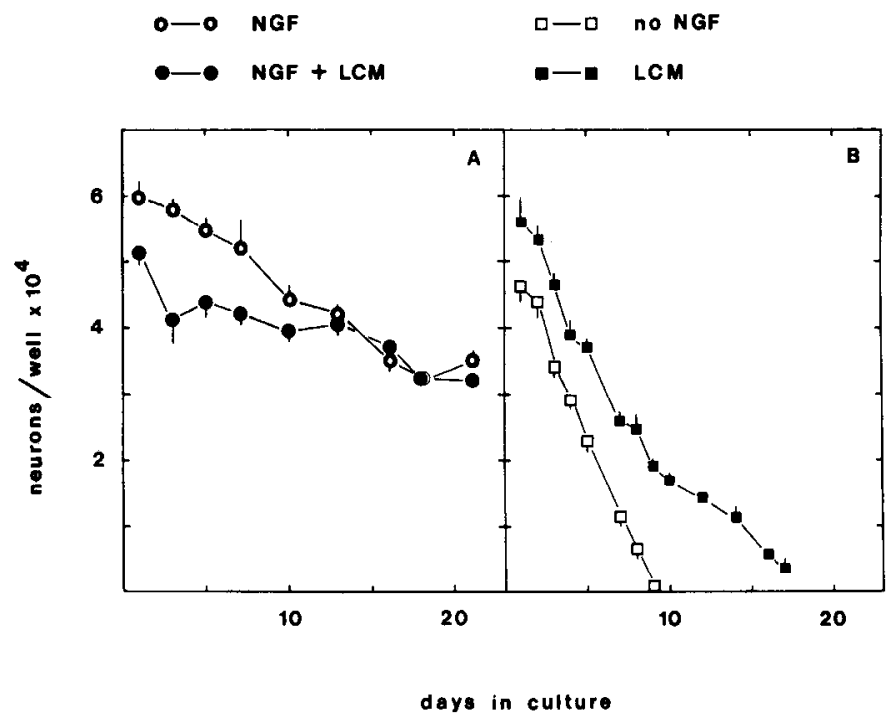

Figure 1. Effect of LCM (10\%) on neuronal survival in the presence $(A)$ and the absence $(B)$ of NGF $(1 \mu \mathrm{g} / \mathrm{ml})$. The neurons were plated at a density of 100-120,000 cells/well and grown for 2 weeks in culture. Only phase-bright cells with one or more processes were counted. Each point represents the mean of 3 culture wells from the same experiment, and the vertical bars indicate the SEM.

\section{Results}

\section{Effect of LCM on neuronal survival}

One day after plating, approximately the same number of SCG neurons from 9-d chick embryos survive in the presence as in the abscncc of NGF (Fig. 1). During the following days, howcver, the number of neurons decreases rapidly in the absence of NGF, whereas in its presence, the cultures can be maintained for several weeks (Zurn and Mudry, 1986; Figs. 1, 2). ${ }^{1}$ LCM cannot replace NGF as a survival factor for the long-term growth of these neurons, although survival is somewhat increased with LCM (Figs. $1 B, 2)$. In the presence of NGF $(1 \mu \mathrm{g} / \mathrm{ml} 7 \mathrm{~S} \mathrm{NGF})$, LCM slightly increases neuronal survival at low (10-30,000 neurons/well), but not at higher (70-100,000 neurons/well), cell density (Fig. 3). This effect on neuronal survival cannot be due to a "neurite-promoting activity" of LCM, since LCM does not promote neurite outgrowth in SCG neurons grown in the presence or the absence of NGF on culture dishes precoated with polyornithine and chick heart cell-conditioned medium (unpublished results).

\section{Effect of LCM on neuronal metabolism}

LCM does not increase neuronal metabolism in SCG neurons grown in the absence of NGF (Fig. 2). Indeed, the cell body diameter is the same in the presence $(11.6 \pm 0.38 \mu \mathrm{m})$ as in the absence (12.5 $\pm 0.22 \mu \mathrm{m} ; n=4 \pm$ SEM) of LCM. In addition, the $\mathrm{LDH}$ activity per neuron and ${ }^{3} \mathrm{H}$-leucine incorporation into proteins are not increased when LCM is present (data not shown). In the presence of NGF, however, LCM stimulates neuronal growth, as reflected by a $1.5-2$-fold increase in the cell body

1 The difference in neuronal survival observed in the experiment shown in Figure $1 A$ is not significant since averages from a larger number of cultures $(9$ different experiments) indicate that approximately the same number of cells survive on culture day 3 whether LCM is present or not: $35.4 \pm 1.5 \%$ and $32 \pm 2.1 \%$ of the cells initially plated survive whether NGF, or NGF and LCM, respectively, is present in the culture medium ( $n=9 \pm$ SEM). 
A

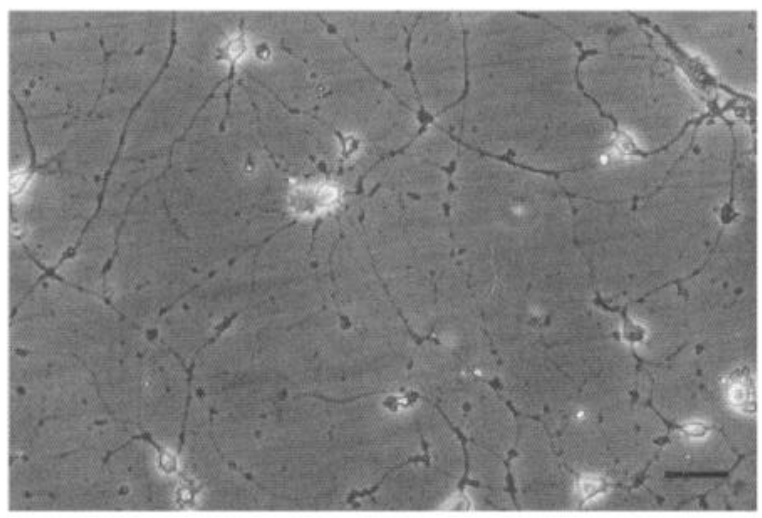

B

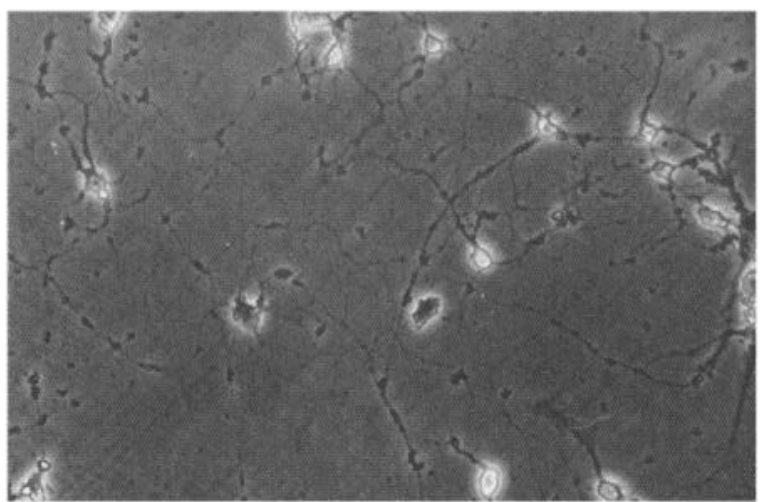

C
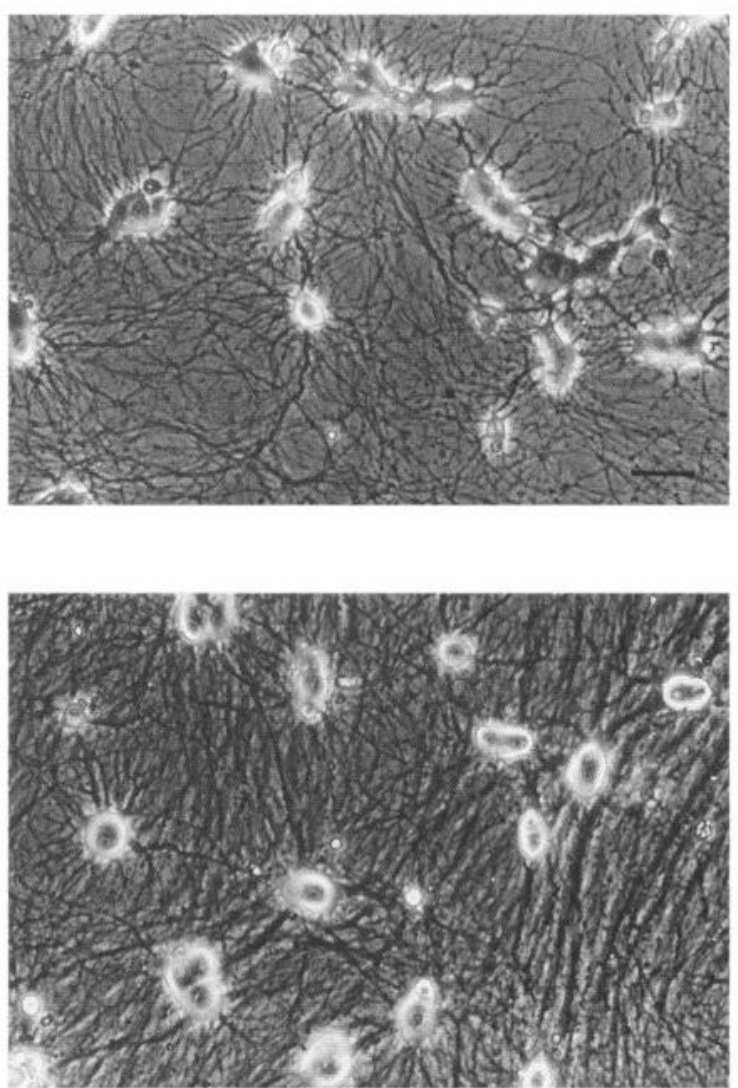

Figure 2. SCG neurons plated at a density of 100-120,000 cells/well and grown for $9 \mathrm{~d}$ in the absence $(A, B)$ or the presence $(C, D)$ of $1 \mu \mathrm{g} / \mathrm{ml}$ NGF. In $B$ and $D$, the culture medium was supplemented with $10 \% \mathrm{LCM}$. Calibration bar, $50 \mu \mathrm{m}$.

diameter (Table 1). The activity of $\mathrm{LDH}$, as well as the incorporation of ${ }^{3} \mathrm{H}$-leucine into neuronal proteins, is also increased severalfold in the presence of LCM (Table 1). This increase is concentration-dependent (Fig. 4) and the time course of its appearance is shown in Figure 6.

\section{Effect of LCM on CA production}

LCM produces a 3-6-fold increase in CA production per neuron in the presence of $\mathrm{NGF}$, whereas $\mathrm{ACh}$ production is decreased to $80 \%$ of control (Table 2 ). This enhancement of CA production is concentration-dependent (Fig. 5) and the time course of its appearance is shown in Figure 6. It is not only due to neuronal growth, since CA synthesis is also enhanced when expressed per ${ }^{3} \mathrm{H}$-leucine-labeled protein (Table 2). However, TH-specific activity is not increased in the presence of LCM (Table 2). The percentage of cells taking up ${ }^{3} \mathrm{H}$-norepinephrine after 4-24 hr in culture is the same in the presence $(78.5 \pm 3.4 \%)$ as in the absence $(76.8 \pm 3.3 \% ; n=8 \pm$ SEM) of LCM. (After $6 \mathrm{~d}$ in culture in the presence of NGF alone, virtually all the neurons take up ${ }^{3} \mathrm{H}$-norepinephrine; Zurn and Mudry, 1986.) In addition, when LCM is added to SCG cultures grown for 1 week in the presence of NGF alone, and then for an additional week in the presence of NGF and LCM, the CA production of these cells is only slightly lower $(2.63 \pm 0.27 \mathrm{fmol} /$ neuron $)$ than that of SCG neurons grown in the presence of LCM from day 1 to day $14(3.22 \pm 0.49 \mathrm{fmol} /$ neuron; $n=4 \pm$ SEM). Neurons grown for 2 weeks in the presence of NGF alone synthesize only $0.78 \pm 0.07 \mathrm{fmol} /$ neuron CA $(n=4 \pm \mathrm{SEM})$.
As is the case for neuronal survival (Fig. 3), the increase in $\mathrm{CA}$ production appears to be density-dependent. Indeed, there is a somewhat larger increase in CA synthesis at a density of 20-40,000 neurons/well $(244 \pm 28 \% ; n=16 \pm$ SEM) than at a density of $60-80,000$ neurons/well $(159 \pm 23 ; n=7 \pm$ SEM). However, additional experiments with a batch of LCM that had a more potent effect on CA production indicate that at high cell densities LCM still stimulates CA production beyond the levels observed for protein synthesis ( $30-40,000$ cells/well: $827 \pm 61 \%$; $70-90,000$ cells/well: $586 \pm 166 \% ; n=4 \pm$ SEM). Note that LCM stimulation of neuronal growth ( ${ }^{3} \mathrm{H}$-leucine incorporation) is the same at low and high cell densities [ $244 \pm 34 \%(n=9)$ and $237 \pm 26 \%(n=3)$, respectively].

\section{Potentiating effect in the presence of high NGF concentrations}

When the SCG neurons are grown at a NGF concentration optimal for neuronal survival (5-10 ng/ml $2.5 \mathrm{~S}$ NGF), LCM stimulates CA production per neuron up to 3-6-fold (Table 2). At a 10-100-fold higher NGF concentration, however, the effect of LCM on CA production is potentiated, since CA synthesis increases as much as 10-15-fold (Figs. 7, 8). Note that in the absence of LCM, high NGF by itself does not enhance CA production by the SCG neurons (Fig. 7). Interestingly, the effect of LCM on neuronal metabolism is not potentiated in the presence of elevated NGF concentrations, i.e., the increase in LDH activity due to the presence of LCM is not higher with an excess of NGF than with normal NGF concentrations $(263 \pm 22 \%$; $n=4 \pm$ SEM and $250 \pm 26 \% ; n=18 \pm$ SEM, respectively). 


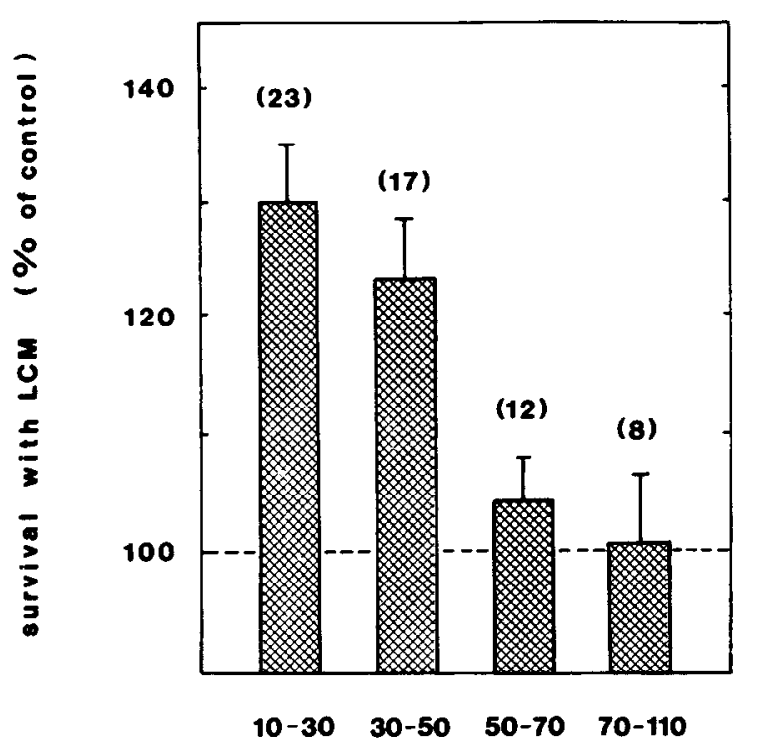

neuronal density $\left(\times 10^{3}\right)$

Figure 3. Density-dependent effect of LCM on the survival of SCG neurons. The neurons were cultured at a plating density of 50-200,000 neurons $/ 16 \mathrm{~mm}$ well in either complete growth medium containing 1 $\mu \mathrm{g} / \mathrm{ml} \mathrm{NGF}$ (control) or in the same medium supplemented with $5-10 \%$ LCM. The results are expressed as percentages of cells surviving after 2 weeks in culture in the presence of LCM as compared to those of control cultures grown in its absence $(100 \%)$. Each value represents the mean of $n$ separate experiments (indicated in brackets) and the vertical bars indicate the SEM.

\section{Partial characterization of the neurotrophic component(s) present in $L C M$}

All the growth- and development-promoting activity of LCM is lost after overnight dialysis against saline in dialysis tubing with a molecular weight cutoff of $1000 \mathrm{Da}$. Conversely, when LCM is filtered through an Amicon YC05 ultrafiltration membrane (Millipore) with a molecular weight cutoff of $500 \mathrm{Da}$, all the activity is found in the filtrate (L500). L500 is not inactivated by repeated freezing and thawing, boiling for $30 \mathrm{~min}(660 \pm$ $33 \%$ and $631 \pm 52 \%$ increases in CA production per neuron before and after boiling, respectively; $n=2 \pm$ SEM), or by treatment with pronase $(323 \pm 27 \%$ and $272 \pm 9 \%$ increases before and after treatment, respectively; $n=2 \pm$ SEM). The proteolytic treatment was performed as follows: $1.5 \mathrm{ml}$ of L500 was incubated with protease from Streptomyces griseus (final concentration, $40 \mu \mathrm{g} / \mathrm{ml}$ ) for $3 \mathrm{hr}$ at $37^{\circ} \mathrm{C}$. The enzyme was then inactivated by boiling for $10 \mathrm{~min}$ and removed by filtration through an Amicon YC05 ultrafiltration membrane.

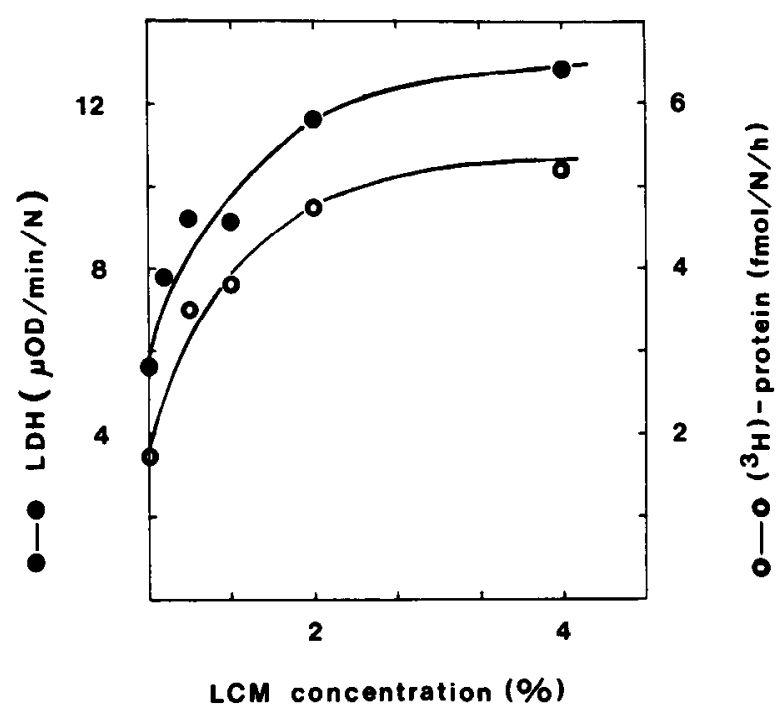

Figure 4. Lactate dehydrogenase (LDH) activity (-) and ${ }^{3} \mathrm{H}$ leucine incorporation into neuronal proteins $(\mathrm{O}-\mathrm{O})$ as functions of LCM concentration in 2-week-old SCG neurons plated at a density of $100-120,000$ cells/well. The LDH activity is measured spectrophotometrically at a wavelength of $340 \mathrm{~nm}$ and is expressed in optical density $(\mu \mathrm{m}) / \mathrm{min} /$ neuron. The amount of TCA-precipitable ${ }^{3} \mathrm{H}$-leucine-labeled protein is expressed in fmol/neuron/hr.

All the neurotrophic activities present in LCM (increased growth, development, and potentiation with high NGF) are found in the L500 fraction of LCM and are resistant to boiling and protease treatment. In one representative experiment, for instance, whole LCM and L500 stimulated growth (LDH activity) 2.7- and 2.8-fold, and CA production 6.9- and 7.1-fold, respectively. Figure 5 shows the dose-dependent increase in CA production with LCM before (LCM) and after (L500) passage through an Amicon YC05 ultrafiltration membrane.

\section{Localization and neuronal specificity of the component(s) present in $L C M$}

A low-molecular-weight component with properties similar to LCM was also found to be present in chick, rat, and human serum, as well as in various organ extracts of the chick (liver, heart, brain, eye, skeletal muscle, SCG) and rat (liver, brain). The organ extracts were prepared from 9-d chick embryos or young adult rats, as described by Lindsay and Rohrer (1985). In this case, however, the supernatants obtained after freezing, homogenization, and high-speed centrifugation were subsequently filtered through an Amicon YC05 ultrafiltration mcmbrane to obtain filtrates containing only components with molecular weights lower than $500 \mathrm{Da}$. The sera were also

Table 1. Effect of LCM on neuronal growth

\begin{tabular}{lrrr} 
& \multicolumn{1}{c}{$\begin{array}{c}\text { NGF }+ \\
\text { LCM }\end{array}$} & $\begin{array}{l}\text { Con- } \\
\text { trol } \\
(\%)\end{array}$ \\
\hline Cell body diameter $(\mu \mathrm{m})(n=6)$ & $17 \pm 0.8$ & $27 \pm 0.9$ & 159 \\
LDH activity (opt dens, $\mu \mathrm{m} /$ neuron $/ \mathrm{min})(n=4)$ & $11.2 \pm 1.6$ & $23.7 \pm 2.5$ & 212 \\
${ }^{3} \mathrm{H}-$ leucine incorporation (protein) $(\mathrm{fmol} /$ neuron $/ \mathrm{hr})(n=9)$ & $3.1 \pm 0.18$ & $7.1 \pm 0.8$ & 229 \\
\hline
\end{tabular}

Each value represents the mean of $n$ separate experiments \pm SEM. All measurements were made using SCG neurons grown in parallel wells for $10-14 \mathrm{~d}$ in the presence or the absence (=control) of LCM. Cell density, 100-120,000 neurons/ well. 


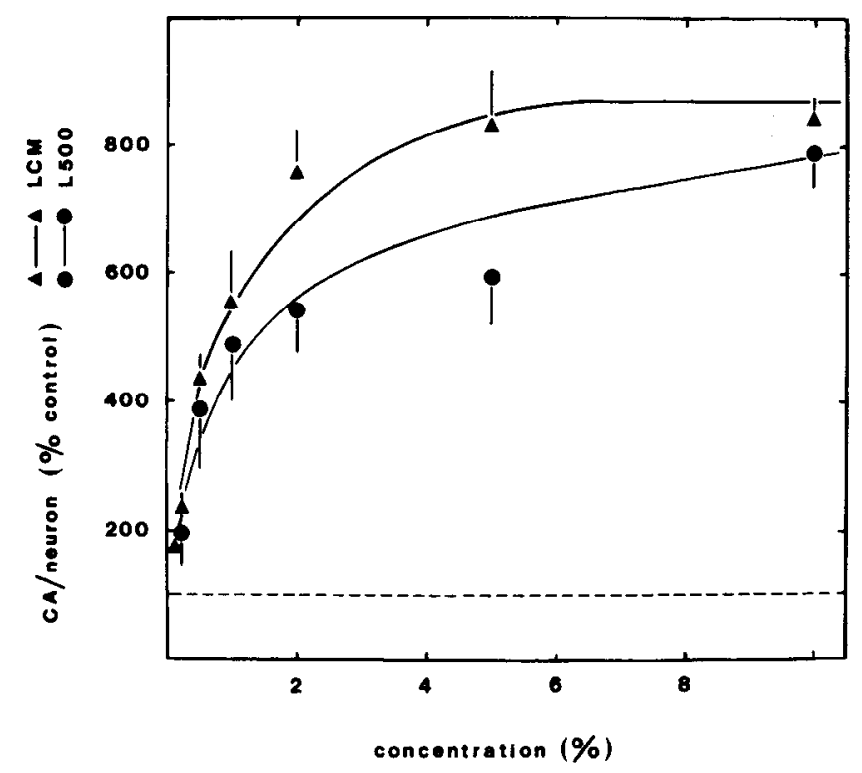

Figure 5. CA production in SCG neurons grown for 2 weeks in the presence of increasing amounts of LCM ( The L500 was prepared from LCM by passage through an Amicon YC05 ultrafiltration membrane with a molecular weight cutoff of $500 \mathrm{Da}$ (same batch). CA synthesis and accumulation were measured after a $4 \mathrm{hr}$ incubation in the presence of ${ }^{3} \mathrm{H}$-tyrosine and are expressed in percentages of the control grown in the presence of NGF alone (100\%). Each point represents the mean of 2-3 separate experiments and the vertical bars indicate the SEM.

ultrafiltrated before addition to the SCG cultures. All the extracts and sera were usually tested at final concentrations of 5\%, and sometimes as high as $20 \%$.

The neurotrophic substance present in LCM appears to be specific for sympathetic neurons since it does not increase neuronal growth or induce CA synthesis in cultured 7-8-d-old chick ciliary and 8-9-d-old chick dorsal root ganglion neurons (data not shown). Cultured chick spinal cord neurons ( $7 \mathrm{~d}$ ) were unresponsive as well (L. Wuarin, unpublished observations).

\section{Discussion}

\section{Effect of LCM on neuronal survival}

LCM cannot substitute for NGF as a survival factor for the long-term growth of chick SCG neurons (Figs. 1, 2). Similarly, LCM does not affect neuronal survival in the presence of NGF and at densities at which survival is optimal. At low neuronal

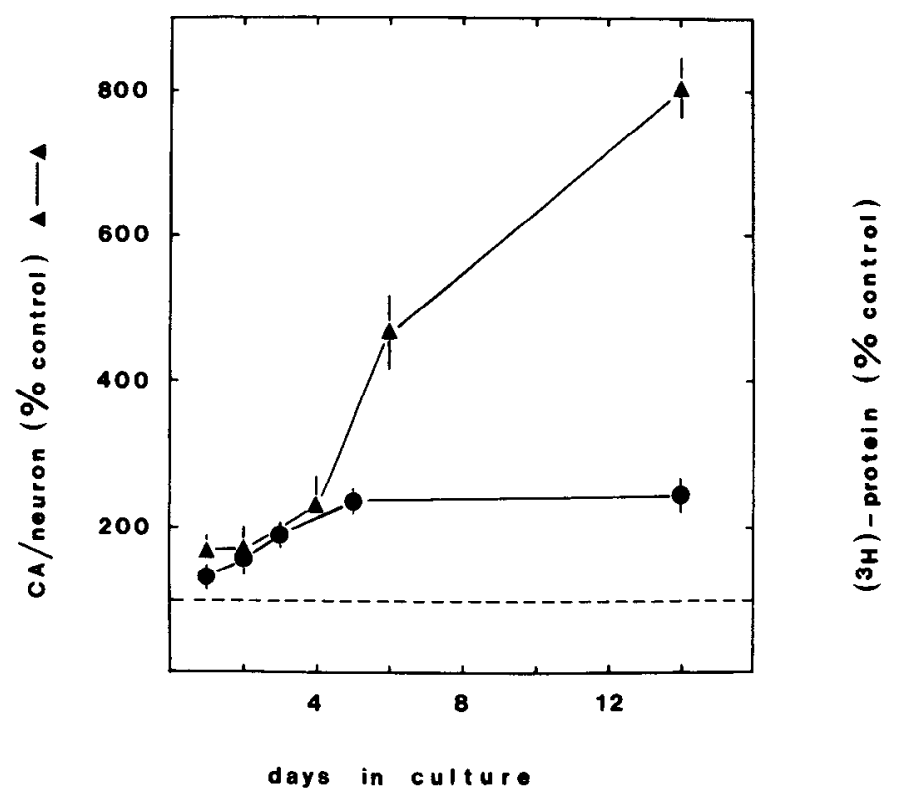

Figure 6. Time course of appearance of the effect of LCM on ${ }^{3} \mathrm{H}$ leucine incorporation into neuronal proteins (-) and on CA production $(\boldsymbol{\Lambda}-\boldsymbol{\Lambda}) .{ }^{3} \mathrm{H}$-labeled proteins and CA production were measured as described in Figure 4 and are expressed in percentages of the control grown in the presence of NGF alone (100\%). Each point represents the mean of 2-3 experiments and the vertical bars indicate the SEM.

densities, however, at which survival in the presence of NGF alone is poor (Zurn and Mudry, 1986), LCM has a small survival effect on the SCG neurons (Fig. 3). Since LCM does not promote neurite outgrowth, this apparent survival effect of LCM might be a secondary consequence of its action on neuronal growth and metabolism (see below).

\section{Effect of LCM on neuronal metabolism}

LCM has an important growth-promoting action on cultured SCG neurons. This activity is dependent on the presence of NGF. LCM increases cell body diameter, LDH activity, and incorporation of ${ }^{3} \mathrm{H}$-leucine into neuronal proteins approximately 2-fold (Table 1). Since this not only occurs at NGF concentrations optimal for neuronal survival $(1-2 \mu \mathrm{g} / \mathrm{ml} 7 \mathrm{~S}$ NGF) but also at those optimal for neuronal growth (4-6 $\mu \mathrm{g} /$ ml) (Zurn and Mudry, 1986, and below), the active compo-

Table 2. Effect of LCM on neuronal differentiation

\begin{tabular}{|c|c|c|c|}
\hline & NGF & $\mathrm{NGF}+\mathrm{LCM}$ & $\begin{array}{l}\text { Con- } \\
\text { trol } \\
(\%)\end{array}$ \\
\hline $\mathrm{CA} /$ neuron $(\mathrm{fmol} /$ neuron $/ \mathrm{hr})(n=10)$ & $0.46 \pm 0.1$ & $2.32 \pm 0.4$ & 504 \\
\hline $\mathrm{CA}{ }^{3} \mathrm{H}-$ protein $(n=8)$ & $0.16 \pm 0.03$ & $0.28 \pm 0.04$ & 174 \\
\hline $\mathrm{ACh} /$ neuron $(\mathrm{fmol} /$ neuron $/ \mathrm{hr})(n=10)$ & $0.12 \pm 0.01$ & $0.097 \pm 0.01$ & 81 \\
\hline $\mathrm{ACh} /{ }^{3} \mathrm{H}$-protein $(n=8)$ & $0.03 \pm 0.003$ & $0.014 \pm 0.003$ & 38 \\
\hline TH activity (fmol/neuron $/ \mathrm{min})(n=6)$ & $7.44 \pm 1.1$ & $16.6 \pm 2.5$ & 223 \\
\hline TH-specific activity $/{ }^{3} \mathrm{H}$-protein $(n=4)$ & $2.7 \pm 0.36$ & $2.4 \pm 0.24$ & 89 \\
\hline
\end{tabular}

Each value represents the mean of $n$ separate experiments \pm SEM. All measurements were made using SCG neurons grown in parallel wells for $10-14 \mathrm{~d}$ in the presence or the absence (= control) of LCM. Cell density, 100-120,000 neurons/ well. 


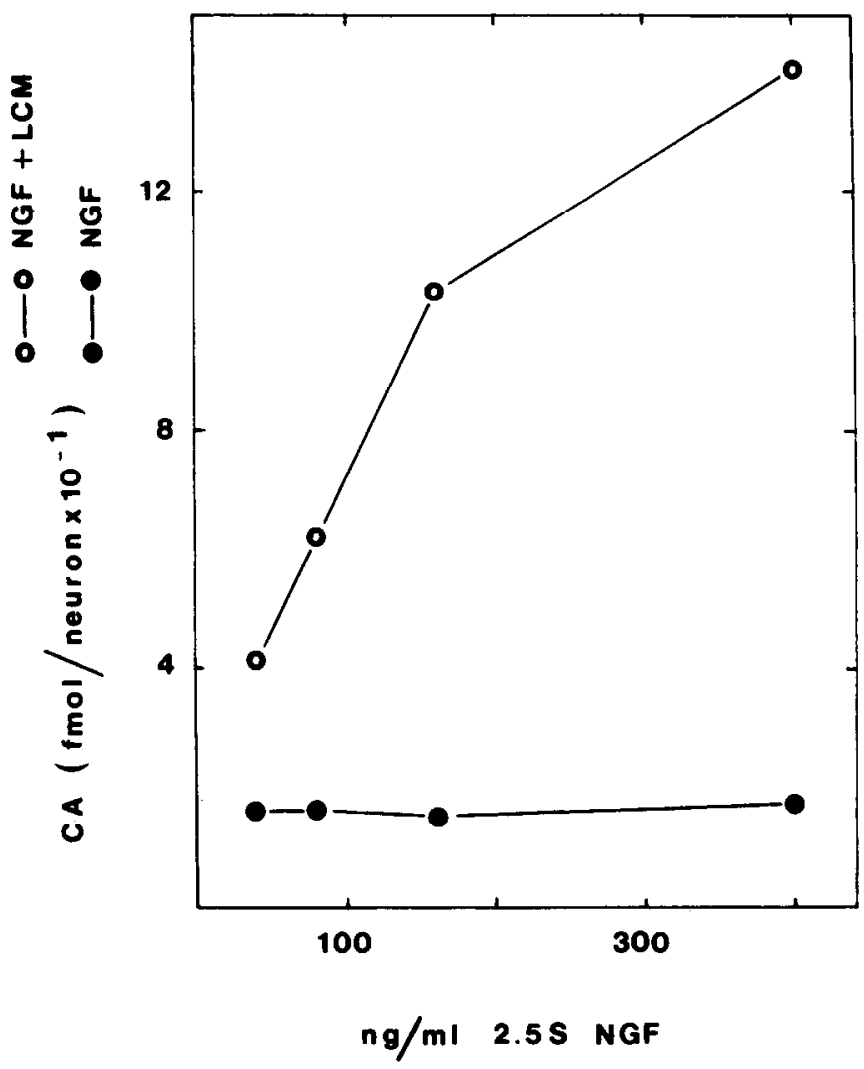

Figure 7. CA production as a function of NGF concentration in SCG neurons plated at a density of 100-120,000 cells/well and grown for 2 weeks in culture in the presence of NGF alone (-) or in NGF and $10 \%$ LCM (O-O). Transmitter production was measured as described in Figure 4 and expressed in $\mathrm{fmol} /$ neuron $/ 4 \mathrm{hr}$.

nent(s) present in LCM cannot be NGF-like.

Factors that promote metabolism in cultured neurons have been described previously. High $\mathrm{K}^{+}$concentrations and a highmolecular-weight component present in chick eye extract, for instance, stimulate the growth of cultured chick ciliary ganglion neurons (Nishi and Berg, $1981 \mathrm{a}, \mathrm{b})$. However, high $\mathrm{K}^{+}(35 \mathrm{~mm})$ does not promote growth in cultured SCG neurons (unpublished observations), but is essential for their long-term survival in the presence of NGF (Zurn and Mudry, 1986).

\section{Effect of LCM on CA production}

The neurotrophic activity present in LCM induces a concentration-dependent increase in CA and a concomitant decrease in ACh production (Zurn and Mudry, 1986; Table 2, Fig. 5). A differential regulation of $\mathrm{CA}, \mathrm{ACh}$, and/or substance $\mathrm{P}$ also occurs in chick SCG neurons with increasing cell density (Zurn and Mudry, 1986) and in rat SCG neurons in the presence of non-neuronal cells or by membrane depolarization (Patterson and Chun, 1977; Kessler et al., 1981; Adler and Black, 1985).

The stimulation of CA production by LCM is greater than the increase in neuronal growth. Thus, the adrenergic properties of the neurons are enhanced. Yet the specific activity of TH is not changed. Therefore, the mechanism by which the neurotrophic component(s) present in LCM specifically increase CA production in the cultured chick SCG neurons has still to be established. It is possible that the activity of dopamine- $\beta$-hydroxylase (responsible for the synthesis of NE from dopamine) is specifically enhanced and thus responsible for the increase in

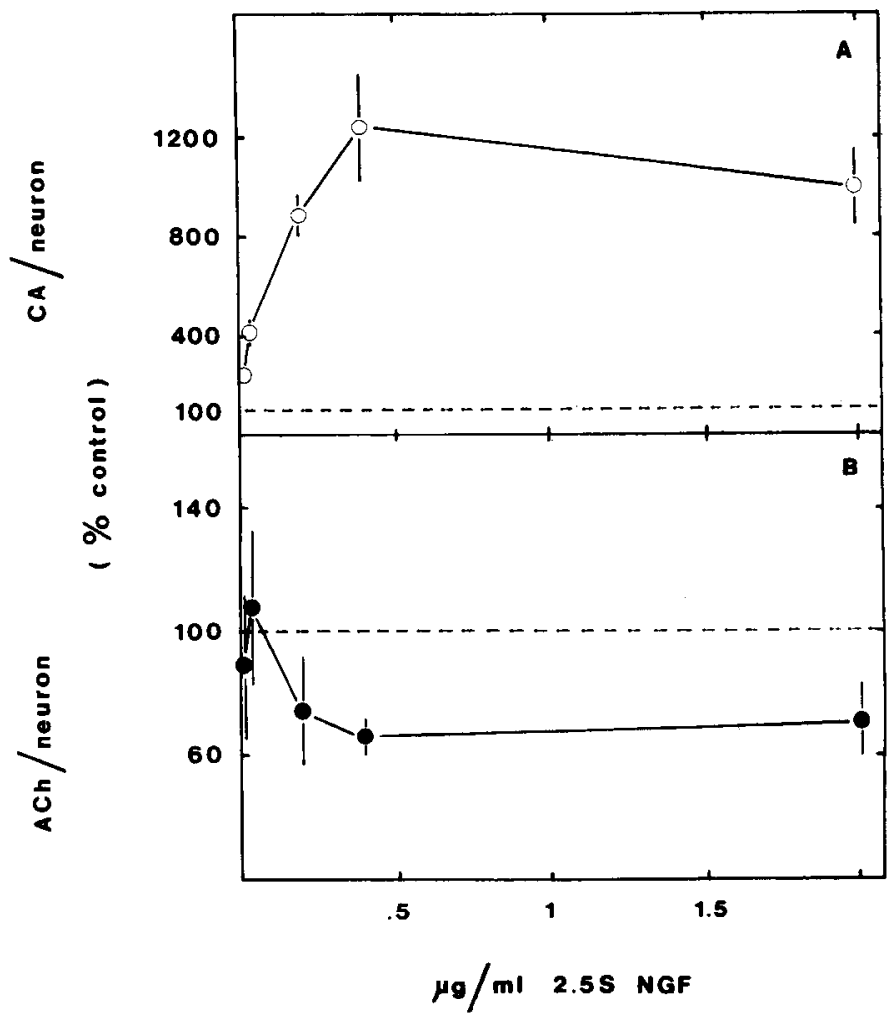

Figure 8. Transmitter synthesis and accumulation in SCG neurons plated at a density of 100-120,000 cells/well and cultured for 2 weeks with increasing concentrations of NGF in the presence or the absence of $10 \%$ LCM. CA $(A)$ and ACh $(B)$ production in the presence of LCM was expressed in percentages of the control grown in the presence of NGF alone (100\%). Each value represents the mean of 4 separate experiments and the vertical bars indicate the SEM.

the adrenergic properties observed (unpublished observations). Alternatively, the degradation or release of CA might be decreased in the presence of LCM (work in preparation). The possibility that LCM might selectively promote the survival of an adrenergic subpopulation of neurons present in these ganglia (Edgar et al., 1981) is unlikely: as described in our previous paper (Zurn and Mudry, 1986) and in Results, the percentage of cells taking up ${ }^{3} \mathrm{H}-\mathrm{NE}$ is the same in the presence or the absence of LCM. Furthermore, LCM increases CA production almost to the same extent if it is added to the cultures 1 week after plating. Thus, although late selection cannot be completely excluded, LCM does not appear to selectively increase the survival of a possible adrenergic subpopulation of neurons, but rather promotes adrenergic development in neurons that, in addition to $\mathrm{CA}$, are also capable of synthesizing some $\mathrm{ACh}$.

The increase in CA production due to LCM is slightly higher at low cell densities, densities at which CA synthesis is low, than at higher cell densities, where CA synthesis in the absence of LCM is already high (Zurn and Mudry, 1986). Note, however, that at a high cell density, CA production is still increased beyond the levels observed for protein synthesis. Increased CA production in the presence of LCM and at high cell density (Zurn and Mudry, 1986) probably does not involve the same molecular mechanisms. Indeed, the neurotrophic activity present in LCM consists of a diffusible substance released by cultured liver cells. The effect of cell density, however, appears to require direct cell contact, since it cannot be transferred with medium conditioned by neurons cultured at high densities (Zurn and 
Mudry, 1986). In addition, neuronal growth does not increase with increasing cell density (Zurn and Mudry, 1986, and Results), whereas LCM increases growth both at low and high cell densities.

\section{Potentiating effect of high $N G F$}

With concentrations of $1 \mu \mathrm{g} / \mathrm{ml} 7 \mathrm{~S}$ or $5-10 \mathrm{ng} / \mathrm{ml} 2.5 \mathrm{~S} \mathrm{NGF}$, optimal survival of cultured sympathetic neurons is obtained (Chun and Patterson, 1977; Greene, 1977; Zurn and Mudry, 1986). At 4-5-fold higher NGF concentrations, neuronal growth and $C A$ production reach higher values, but there is no additional effect on survival (Zurn and Mudry, 1986). With still higher NGF concentrations (200-500 ng/ml 2.5 S NGF), no additional increase in growth and CA production is observed (Fig. 7, lower curve; Zurn and Mudry, 1986). However, in the presence of this large excess of NGF, the effect of LCM on CA production, but not on neuronal growth, is potentiated (Figs. 7, 8). Thus NGF appears to potentiate the effect of LCM on CA production. Conversely, since the neurotrophic effects of LCM appear to depend on the presence of NGF, and since a 4-5-fold excess of NGF increases CA synthesis (Zurn and Mudry, 1986), it is possible that LCM potentiates the effect of NGF on CA production rather than the reverse. It has been shown, for instance, that laminin modulates the effect of NGF on neurite outgrowth and neuronal survival, while it has no survival-promoting activity itself (Edgar and Thoenen, 1982). Since it is difficult to know whether LCM potentiates NGF, or if NGF potentiates LCM, we can at least say that NGF and LCM have a synergistic action on CA production by SCG neurons.

\section{Partial characterization of the neurotrophic component(s) present in LCM}

The neurotrophic component(s) present in LCM has a molecular weight lower than $500 \mathrm{Da}$, since all of its activities (growth, differentiation, and potentiation with high NGF) filter through an ultrafiltration membrane with a molecular weight cutoff of $500 \mathrm{Da}$. No loss in activity is found after heat or proteolytic treatment.

Recently, several very low-molecular-weight neurotrophic components have been described. Pyruvate, for instance, appears to be the main trophic component of glia-conditioned medium, which is responsible for the survival of central nervous system neurons cultured in the absence of recognized protein neurotrophic factors (Selak et al., 1985). Ascorbate, the cofactor of the enzyme dopamine- $\beta$-hydroxylase, increases the epinephrine and norepinephrine content of cultured adrenal chromaffin cells (Wilson and Kirshner, 1983). L-Glutamic acid has also been shown to have neurotrophic activity. It was found to oppose the decrease in AChE and butyrylcholinesterase in the SCG of the cat that otherwise occurs after preganglionic denervation (Koelle et al., 1986). However, neither pyruvate $\left(10^{-3} \mathbf{M}\right)$, ascorbate $(250 \mu \mathrm{M})$, nor L-glutamic acid $\left(10^{-4} \mathrm{M}\right)$ was able to mimic the neurotrophic effects of LCM on the SCG neurons (unpublished observations). Similarly, glutathione $\left(10^{-5} \mathbf{M}\right)$, which has a pleiotypic effect on cells (Meister and Anderson, 1983), biopterin (a cofactor of $\mathrm{TH}$ ) and hydrocortisone (Zurn and Mudry, 1986), putrescine $\left(5 \times 10^{-4} \mathrm{M}\right)$, biotin $(1 \mu \mathrm{g} / \mathrm{ml})$, fumaric acid $(25 \mu \mathrm{g} / \mathrm{ml})$, and inositol $\left(10^{-3} \mathrm{M}\right)$ show no neurotrophic activity on the SCG neurons (unpublished observations).

\section{Localization and neuronal specificity of the neurotrophic activity present in LCM}

Adrenergic neurotrophic activity is present in medium conditioned by cultured chick embryo liver cells, but not in medium conditioned by chick heart cells or SCG non-neuronal cells. A low-molecular-weight component(s) with properties very similar to LCM was found to be present in various chick embryo organ extracts, as well as in chick serum. Thus, the neurotrophic activity does not appear to have any organ specificity or to be confined to target organs of the sympathetic nervous system (cf. the presence of the activity in skeletal muscle extract). A possible explanation is that the component(s) is circulating in the blood and/or is present in the endothelial cells of the blood vessels. In addition, the adrenergic neurotrophic substance is not speciesspecific, since it is also present in serum, and in liver and brain extract from the rat.

Although there is apparently no specific localization of the adrenergic neurotrophic component, a specificity seems to reside in its neuronal targets. Indeed, the neurotrophic component(s) appears to affect only sympathetic neurons, since it does not increase neuronal growth or induce CA production in cultured chick ciliary ganglion, DRG, or spinal cord neurons. Its specificity is therefore different from that of NGF. It will be interesting to test whether sympathetic neurons from the rat, for instance, also respond to the neurotrophic component.

In summary, medium conditioned by cultured chick liver cells contains a low-molecular-weight neurotrophic substance that promotes neuronal metabolism and CA production in dissociated chick SCG neurons cultured in the presence of NGF. This component has little effect on neuronal survival and shows no neurite-promoting activity. It appears to be specific for sympathetic neurons, since it does not increase neuronal growth or induce CA production in other types of cultured chick neurons. This component is thus clearly distinct from other known factors. Work is in progress to further characterize the biochemical nature of the neurotrophic activity present in LCM.

\section{References}

Acheson, A. L., and H. Thoenen (1983) Cell contact-mediated regulation of tyrosine hydroxylase synthesis in cultured bovine adrenal chromaffin cells. J. Cell Biol. 97: 925-928.

Acheson, A. L., D. Edgar, R. Timpl, and H. Thoenen (1986) Laminin increases both levels and activity of tyrosine hydroxylase in calf adrenal chromaffin cells. J. Cell Biol. 102: 151-159.

Adler, J. E., and I. B. Black (1985) Sympathetic neuron density differentially regulates transmitter phenotypic expression in culture. Proc. Natl. Acad. Sci. USA 82: 4296-4300.

Barbin, G., M. Manthorpe, and S. Varon (1984) Purification of the chick eye ciliary neuronotrophic factor. J. Neurochem. 43: 14681478.

Barde, Y. A., D. Edgar, and H. Thoenen (1982) Purification of a new neurotrophic factor from mammalian brain. EMBO J. 1: 549-553.

Burton, L. E., W. Wilson, and E. M. Shooter (1978) Nerve growth factor in mouse saliva. Rapid isolation procedures for and characterization of 7S nerve growth factor. J. Biol. Chem. 253: 7807-7812.

Chun, L. L., and P. H. Patterson (1977) Role of nerve growth factor in the development of rat sympathetic neurons in vitro. I. Survival, growth and differentiation of catecholamine production. J. Cell Biol. 75: 694-704.

Edgar, D., and H. Thoenen (1982) Modulation of NGF-induced survival of chick sympathetic neurons by contact with a conditioned medium factor bound to culture substrate. Dev. Brain Res. 5: 89-92

Edgar, D., Y. A. Barde, and H. Thoenen (1981) Subpopulations of cultured chick sympathetic neurons differ in their requirements for survival factors. Nature 289: 294-295.

Fukada, K. (1985) Purification and partial characterization of a cho- 
linergic neuronal differentiation factor. Proc. Natl. Acad. Sci. USA 82: 8795-8799.

Greene, L. A. (1977) Quantitative in vitro studies on the nerve growth factor requirements of neurons. I. Sympathetic neurons. Dev. Biol. 58: $96-105$

Gurney, M. E., S. P. Heinrich, M. R. Lee, and H. S. Yin (1986) Molecular cloning and expression of neuroleukin, a neurotrophic factor for spinal and sensory neurons. Science 234: 566-574.

Hefti, F., H. Gnahn, M. E. Schwab, and H. Thoenen (1982) Induction of tyrosine hydroxylase by nerve growth factor and by elevated $\mathrm{K}^{+}$ concentrations in cultures of dissociated sympathetic neurons. J. Neurosci. 2: 1554-1566.

Hildebrand, J. G., D. L. Barber, E. Herbert, and E. Kravitz (1971) Screening for neurotransmitters: A rapid radiochemical procedure. J. Neurobiol. 2: 231-246.

Howard, M. J., and M. Bronner-Fraser (1986) Neural tube-derived factors influence differentiation of neural crest cells in vitro: Effects on activity of neurotransmitter biosynthetic enzymes. Dev. Biol. 117 . 45-54.

Kato, A. C., and M. J. Rey (1982) Chick ciliary ganglion in dissociated cell culture. I. Cholinergic properties. Dev. Biol. 94: 121-130.

Kato, A. C., G. Touzeau, D. Bertrand, and C. R. Bader (1985) Human spinal cord neurons in dissociated monolayer cultures: Morphological, biochemical and electrophysiological properties. J. Neurosci. 5: 2750-2761.

Kessler, J. A., J. E. Adler, M. C. Bohn, and I. B. Black (1981) Substance $P$ in principal sympathetic neurons: Regulation by impulse activity. Science 214: 335-336.

Koelle, G. B., U. J. Sanville, N. S. Thampi, and S. J. Wall (1986) L-Glutamic acid, a neurotrophic factor for maintenance of acetylcholinesterase and butyrylcholinesterase in the preganglionically denervated superior cervical ganglion of the cat. Proc. Natl. Acad. Sci. USA 83: 2751-2754.

Lindsay, R. M., and H. Rohrer (1985) Placodal sensory neurons in culture: Nodose ganglion neurons are unresponsive to NGF, lack NGF receptors but are supported by a liver-derived neurotrophic factor. Dev. Biol. 112: 30-48.

Mains, R. E., and P. H. Patterson (1973) Primary cultures of dissociated sympathetic neurons. I. Establishment of long-term growth in culture and studies of differentiated properties. J. Cell Biol. 59: 329-345.

Meister, A., and M. E. Anderson (1983) Glutathione. Annu. Rev. Biochem. 52: 711-760.

Nishi, R., and $\mathrm{D}$. Berg (1981a) Effects of high $\mathrm{K}^{+}$concentrations on the growth and development of ciliary ganglion neurons in cell culture. Dev. Biol. 87: 301-307.

Nishi, R., and D. Berg (1981b) Two components from eye tissue that differentially stimulate the growth and development of ciliary ganglion neurons in cell culture. J. Neurosci. 1 : 505-513.

Otten, U., and H. Thoenen (1976) Selective induction of tyrosine hydroxylase and dopamine-b-hydroxylase in sympathetic ganglia in organ culture: Role of glucocorticoids as modulators. Mol. Pharmacol. 12: 353-361.

Patterson, P. H., and L. L. Chun (1977) The induction of acetylcholine synthesis in primary cultures of dissociated rat sympathetic neurons. I. Effect of conditioned medium. Dev. Biol. 56: 263-280.

Rohrer, H., A. Acheson, J. Thibault, and H. Thoenen (1986) Developmental potential of quail dorsal root ganglion cells analyzed in vitro and in vivo. J. Neurosci. 6: 2616-2624.

Selak, I., S. D. Skaper, and S. Varon (1985) Pyruvate participation in the low molecular weight trophic activity for central nervous system neurons in glia-conditioned media. J. Neurosci. 5: 23-28.

Sieber-Blum, M., F. Sieber, and K. M. Yamada (1981) Cellutar fibronectin promotes adrenergic differentiation of quail neural crest cells in vitro. Exp. Cell Res. 133: 285-295.

Smith, J., and M. Fauquet (1984) Glucocorticoids stimulate adrenergic differentiation in cultures of migrating and premigratory neural crest. J. Neurosci. 4: 2160-2172.

Sonderegger, P., M. C. Fishman, M. Bokoum, H. C. Bauer, E. A. Neale, and P. G. Nelson (1984) A few axonal proteins distinguish ventral spinal cord neurons from dorsal root ganglion neurons. J. Cell Biol. 98: 364-368.

Swerts, J. P., A. Le Van Thal, A. Vigny, and M. Weber (1983) Regulation of enzymes responsible for neurotransmitter synthesis and degradation in cultured rat sympathetic neurons. Dev. Biol. 100: 111.

Thoenen, H., and Y. A. Barde (1980) Physiology of nerve growth factor. Physiol. Rev. 60: 1284-1335.

Weber, M.J., B. Raynaud, and C. Delteil (1985) Molecular properties of a cholinergic differentiation factor from muscle conditioned medium. J. Neurochem. 45: 1541-1548.

Wilson, S. P., and N. Kirshner (1983) Effects of ascorbic acid, dexamethasone, and insulin on the catecholamine and opioid peptide stores of cultured adrenal medullary chromaffin cells. J. Neurosci. 3: 1971-1978.

Xue, Z. G., J. Smith, and N. M. Le Douarin (1985) Differentiation of catecholaminergic cells in cultures of embryonic avian sensory ganglia. Proc. Natl. Acad. Sci. USA 82: 8800-8804.

Yankner, B. A., and E. M. Shooter (1982) The biology and mechanism of action of nerve growth factor. Annu. Rev. Biochem. 51: 845-868.

Zurn, A., and F. Mudry (1986) Conditions increasing the adrenergic properties of dissociated chick superior cervical ganglion neurons grown in long-term culture. Dev. Biol. 117: 365-379. 